\title{
SINGLE-PHASE CONVECTIVE HEAT TRANSFER AND PRESSURE DROP COEFFICIENTS IN CONCENTRIC ANNULI
}

\author{
Warren R. Van Zyl, Jaco Dirker*, Josua P. Meyer \\ 0002 . \\ South Africa \\ Tel: +27 12420 2465, fax: +27 420 6632, e-mail: jaco.dirker@up.ac.za \\ *Author for correspondence
}

Department of Mechanical and Aeronautical Engineering, University of Pretoria, Pretoria,

\begin{abstract}
Varying diameter ratios associated with smooth concentric tube-in-tube heat exchangers are known to have an effect on their convective heat transfer capabilities. Linear and non-linear regression models exist for determining the heat transfer coefficients, however, these are complex and time consuming, and require much experimental data in order to obtain accurate solutions. A large dataset of experimental measurements on heat exchangers with annular diameter ratios of $0.483,0.579,0.593$ and 0.712 with respective hydraulic diameters of $17.01 \mathrm{~mm}, 13.84 \mathrm{~mm}, 10.88 \mathrm{~mm}$ and $7.71 \mathrm{~mm}$ was gathered. Mean Nusselt numbers were determined using the modified Wilson plot method, a non-linear regression scheme and the logarithmic mean temperature difference method. These three methods presented disagreements with existing correlations based on local wall temperatures. The local Nusselt numbers were determined using the logarithmic mean temperature difference method. Local wall temperature measurements were made using a novel method which minimized obstructions within the annulus. Friction factors were calculated directly from measured pressure drops across the annuli. Both heated and cooled horizontal annuli in fully turbulent
\end{abstract}


flow with Reynolds numbers based on the hydraulic diameter varying from 10000 to 45000 with water as the working medium were investigated.

\section{INTRODUCTION}

Convection heat transfer is the main heat transfer mechanism in most heat exchangers. It is essential that convection heat transfer and friction factors are thoroughly understood in order to optimally design heat exchangers. The tube-in-tube heat exchanger with a counter flow configuration operating in the turbulent flow regime is one of the simplest types of heat exchangers. Gnielinski [1] reports that correlations for the heat transfer coefficients and friction factors for such heat exchanger types have been found to be inconsistent with each other. The annular diameter ratio, which is defined as the ratio of the inner tube's outer diameter to the outer tube's inner diameter has been reported to influence both the heat transfer and pressure drop within the annulus. Due to the complexities of turbulent flow, it is required that experimental data be used to determine correlations for heat transfer coefficients and friction factors within the annulus.

Table 1 provides recently published correlations (equations 1 to 5 ) for determining mean Nusselt numbers. Gnielinski [1] based a correlation on heat transfer coefficients in turbulent pipe flow, which was extended to include effects of the annular diameter ratio. Dirker and Meyer [2] investigated eleven available correlations and compared them with data obtained from their work. They found differences of up to $20 \%$ in the available correlations and as a result, presented their own correlation. Gnielinski [3] modified the correlation in [1] to fit more recent experimental data including that of Dirker and Meyer [2]. Gnielinski [3] also reports that heat transfer is influenced by the direction of heat flux across the wall when the fluids physical properties are temperature dependent (no direct investigations into the effect 
of the direction of heat flux across the wall are known of). Lu and Wang [4] investigated heat transfer characteristics of water flow through both a horizontal and a vertical annulus with an annular diameter ratio of 0.795 . Swamee et al. [5] modified the smooth tube Sieder and Tate correlation to optimize the design of tube-in-tube heat exchangers. The equation of Dittus and Boelter [6] is included in Table 1 for comparison.

The friction factor within an annulus is also dependent on the annular diameter ratio, and differs from that of a circular tube due to the different velocity profiles. Table 2 provides available correlations for friction factors (equations 6 to 9) within an annulus. Kaneda et al. [7] performed direct numerical simulations on annular flow and proposed their equation based on wall shear stresses. Jones and Leung [8] used a laminar correction factor for smooth annuli to modify the Reynolds number based on the hydraulic diameter. This modification was used in the Prandtl friction factor for turbulent flow in smooth tubes. Gnielinski [3] used a large number of available experimental data to produce a correlation which was based on a modified correlation for turbulent friction factors in smooth tubes. The Blasius equation [9] is also included in Table 2 for comparison purposes. As with the heat transfer correlations, there are no known investigations regarding the influence of the direction of heat flux on the friction factor.

In this study, large data sets with relatively high accuracy were obtained from experimental measurements. Both heated and cooled annuli were tested to consider the effects of the direction of heat flux across the wall, on both heat transfer coefficients and friction factors. Wall temperatures on both the inner-tube wall and annulus wall were measured directly. Using the wall temperature measurements, local heat transfer coefficients in the annulus were investigated. 


\section{EXPERIMENTAL FACILITY}

The experimental facility was a closed-loop system designed in such a way as to accommodate heat exchangers of different sizes, with the option of having either a heated or cooled annulus. Refer to Figure 1. Block i represents the cold water supply and block ii the warm water supply.

Cold water was stored in a $1 \mathrm{~m}^{3}$ tank (item 2) and was connected to a $16 \mathrm{~kW}$ cooling unit (item 1). Valves (items 4a and 4b) were used to control fluid flow, to either the test section or returned to the storage tank in a bypass line. Water in the inner tube was pumped using a positive displacement pump (item 3a) with a maximum flow rate of $1.9 \mathrm{~m}^{3} / \mathrm{h}$. The flow rate was controlled using a vector drive coupled to the pump motor. Pulsations in the flow were damped using a $0.004 \mathrm{~m}^{3}$ accumulator (item 5a). Fluid flow rates were obtained with a Coriolis flow meter (item 6a) with an effective range of $0.055 \mathrm{~m}^{3} / \mathrm{h}-2.182 \mathrm{~m}^{3} / \mathrm{h}$. The water passed through the test section (item 10) and returned to the storage tank. A non-return valve (item 7a) was used to avoid backflow.

The other loop was equipped with a $0.6 \mathrm{~m}^{3}$ storage tank (item 8) and was heated with a $12 \mathrm{~kW}$ electrical resistance heater. The water in the annulus was pumped using a $6 \mathrm{~m}^{3} / \mathrm{h}$ centrifugal pump. Valves (items $4 \mathrm{c}$ and $4 \mathrm{~d}$ ) were used to control fluid flow, to either the test section or returned to the storage tank in a bypass line. The flow rate was controlled using a vector drive coupled to the pump motor. Pulsations in the flow were damped using a $0.01 \mathrm{~m}^{3}$ accumulator (item 5b). A Coriolis flow meter (item 6b) with a range of $0.175 \mathrm{~m}^{3} / \mathrm{h}-6.8 \mathrm{~m}^{3} / \mathrm{h}$ was fitted to measure flow rates. The water passed through the test section (item 10). A non-return valve (item 7b) was used to prevent backflow.

Three pressure transducers with interchangeable diaphragms (item 9) were connected to the inlet and outlet of the annulus. The three pressure transducers were calibrated between 
$0 \mathrm{kPa}$ and $22 \mathrm{kPa}, 0 \mathrm{kPa}$ and $35 \mathrm{kPa}$ and $0 \mathrm{kPa}$ and $140 \mathrm{kPa}$ with accuracies of $0.25 \%$ of their full scale values. Each diaphragm used with the differential pressure transducers was calibrated using a dead weight system.

All thermocouples were calibrated against a Pt100 with a manufacturer specified uncertainty of $0.1{ }^{\circ} \mathrm{C}$. By using fluid properties calculated from formulae proposed by Popiel and Wojtkowiak [10] and the method of Kline and McClintock [11], uncertainties on the instruments and measured parameters were determined. The uncertainties for the instruments are listed in Table 3, while those for the measured parameters are provided in Table 4.

\section{TEST SECTION}

A total of four counterflow heat exchanger test sections all with different annular diameter ratios, schematically represented in Figure 2, were built and tested. The annular diameter ratio is defined as:

$$
a=\frac{D_{1}}{D_{o}}(0 \leq a \leq 1)
$$

The limiting case of $a=0$ is a circular tube with an infinitesimal thin wire at the center, and $a=1$ is a parallel-plate geometry.

Figure 3 shows a cross-sectional view of the heat exchanger indicating relevant dimensions and boundary conditions. Major dimensions for the test sections are included in Table 5. The inner tube was constructed from a $5.5 \mathrm{~m}$ long hard-drawn copper tube. Nine measurement stations were equally spaced along the length of the inner tube. Each station had two T-type thermocouples attached and spaced $180^{\circ}$ apart within the inner-tube wall.

Figure 4 shows the attachment of the thermocouples within a section of the inner-tube wall. This was achieved by machining a groove into the tube wall and soldering the thermocouple 
junctions within the groove, leaving no protrusions on the outer wall of the inner tube. The thermocouple wires were fed through a $1.2 \mathrm{~mm}$ diameter hole drilled through the inner-tube wall and retrieved at the ends of the inner tube. The tube was parted near the centre to simplify feeding the thermocouples through the tube. The tube was later reattached with a copper bush on the inside of the inner tube. Four thermocouples were also attached and spaced at $90^{\circ}$ around the periphery of the inner-tube inlet and outlet. These were used to measure the inlet and outlet fluid temperatures.

The outer tube was constructed from hard-drawn copper sections $625 \mathrm{~mm}$ in length. The outer-tube sections resulted in nine control volumes along the test section length. The outertube sections were attached concentrically around the inner tube using spacers integrated into straight couplings. Figure 5 shows a cross-section of the couplings used. On each section, a thermocouple was placed on the outer wall of the annulus tube. These thermocouples were axially spaced in between two inner-tube thermocouple stations. Sufficient insulation was placed around the annulus tube to ensure that the heat loss to the ambient was less than $0.4 \%$ of the exchanged heat, for all test sections.

Pressure drops across the annulus length were measured by means of pressure ports fixed on the outer walls of the annulus. Two pressure taps $180^{\circ}$ apart were located at the inlet and two at the outlet of the annulus (see Figure 2).

\section{EXPERIMENTAL PROCEDURE}

Experimental tests were performed over a wide range of flow rate combinations of the inner tube and annulus. A larger spectrum of annular flow rates were covered, due to the annulus being of primary interest in this study. Experiments were performed with the inlet temperatures to the annulus and inner tube constant at approximately $20{ }^{\circ} \mathrm{C}$ and $55^{\circ} \mathrm{C}$. The inner-tube flow rate was held constant while altering the annular flow rate through a 
spectrum. Once sufficient data points were captured, the inner-tube flow rate was altered and the process repeated. Data was logged once steady-state conditions were reached and desirable energy balances were obtained. Acceptable steady-state conditions were achieved when the inner tube and annulus outlet temperatures changed by less than $0.1{ }^{\circ} \mathrm{C}$ over 30 seconds. This procedure was performed for the case of both a heated annulus and cooled annulus. Energy balance errors below $2 \%$ and $4 \%$ for a heated and a cooled annulus respectively, were achieved. The energy balance error is calculated as:

$$
e b=\frac{\left|\dot{Q}_{i}-\dot{Q}_{o}\right|}{\left(\dot{Q}_{i}+\dot{Q}_{o}\right) / 2}
$$

Here, the heat transfer rates refer to the annulus fluid $\left(\dot{Q}_{o}\right)$ and inner-tube fluid $\left(\dot{Q}_{i}\right)$.

\section{DATA REDUCTION}

Three methods were used to calculate the mean heat transfer coefficients, namely the modified Wilson plot method of Briggs and Young [12], the non-linear regression scheme of Khartabil and Christensen [13] and the logarithmic mean temperature difference (LMTD) method. The latter was also used to calculate the local heat transfer coefficient.

\section{Method 1: Linear Regression Scheme}

With the linear regression analysis, the modified Wilson plot method of Briggs and Young [12] was used to obtain the values of the $C_{i}, C_{o}$ and $P$ in the following Sieder and Tate-type equations:

$$
\begin{gathered}
N u_{i}=\frac{h_{i} D_{i}}{k_{i}}=C_{i} \operatorname{Re}_{i}^{0.8} \operatorname{Pr}_{i}^{\frac{1}{3}}\left(\frac{\mu_{i}}{\mu_{i w, i}}\right)^{0.14} \\
N u_{D h}=\frac{h_{o} D_{h}}{k_{o}}=C_{o} \operatorname{Re}_{D_{h}}^{P} \operatorname{Pr}_{o}^{\frac{1}{3}}\left(\frac{\mu_{o}}{\mu_{i w, o}}\right)^{0.14}
\end{gathered}
$$


Here $\mu_{i w, i}$ and $\mu_{i w, o}$ are the fluid viscosities at the inner surface and outer surface of the inner wall respectively. This method requires a large data set of inlet and outlet temperatures, for the inner tube and annular flows, as well as the associated flow rates.

\section{Method 2: Non-Linear Regression Scheme}

The method of Khartabil and Christensen [13] uses a non-linear regression model to determine the values of $C_{i}, C_{o}$ and $P$ in equation (12) and (13). $C_{i}$ and $C_{o}$ are determined through Gauss elimination and $P$ is solved numerically using a bisection method.

The exponent for the Reynolds number for the inner tube was set to be constant at 0.8 . See equation (12). It was found that the further the exponent value is from 0.8 , the agreement between the linear regression, the non-linear regression and the mean LMTD method reduces. The value of 0.8 is also suggested by Briggs and Young [12] as well as by Khartabil and Christensen [13].

\section{Method 3: LMTD Method}

The LMTD method was used to calculate both the mean heat transfer coefficients as well as the local heat transfer coefficients, based on the averaged and local inner-wall temperatures respectively. The average inner-wall temperature was calculated as follows:

$$
\bar{T}_{i w}=\frac{1}{N_{i}} \sum_{j=1}^{N_{i}} T_{i w, j}
$$

Where $N_{i}$ is the number of thermocouples placed on the inner wall (18 were used in this study).

Heat transfer results were analyzed using both mean and local methods. The mean annulus heat transfer coefficient is defined as: 


$$
h_{L M T D}=\frac{\bar{Q}}{A_{S} \Delta T_{L M T D}}
$$

With $A_{s}$ the wall surface area defined as:

$$
A_{s}=\pi D_{1} L_{h x}
$$

The average rate of heat transfer to the fluid, $\bar{Q}$, is given as:

$$
\bar{Q}=\frac{\left|\dot{Q}_{i}\right|+\left|\dot{Q}_{o}\right|}{2}
$$

The heat transfer rate to the annulus fluid $\left(\dot{Q}_{o}\right)$ and inner-tube fluid $\left(\dot{Q}_{i}\right)$ is calculated with:

$$
\begin{gathered}
\dot{Q}_{o}=\dot{m}_{o} C_{p}\left(T_{o o}-T_{o i}\right) \\
\dot{Q}_{i}=\dot{m}_{i} C_{p}\left(T_{i o}-T_{i i}\right)
\end{gathered}
$$

Fluid properties were calculated from formulae proposed by Popiel and Wojtkowiak [10] at the average bulk temperature, approximated for the annulus as:

$$
T_{b}=\frac{T_{o i}+T_{o o}}{2}
$$

The logarithmic mean temperature difference for the annulus side is defined as:

$$
\Delta T_{L M T D}=\frac{\left(\bar{T}_{i w}-T_{o i}\right)-\left(\bar{T}_{i w}-T_{o o}\right)}{\ln \left[\left(\bar{T}_{i w}-T_{o i}\right) /\left(\bar{T}_{i w}-T_{o o}\right)\right]}
$$

With $\bar{T}_{i w}$ the mean wall temperature given in equation (14).

The dimensionless Nusselt number for the annulus is defined as:

$$
N u_{D h, L M T D}=\frac{h D_{h}}{k}
$$


Where $k$ is the thermal conductivity of the annulus fluid and, $D_{h}$ the hydraulic diameter defined as:

$$
D_{h}=D_{o}-D_{1}
$$

The mean Reynolds number based on the hydraulic diameter of the annulus is defined as:

$$
R e_{D h}=\frac{\dot{m}_{o} D_{h}}{\mu_{o} A_{o}}
$$

Where $A_{o}$ is the cross-sectional area of the annulus, and $\mu_{o}$ the annulus fluid viscosity.

To calculate the local heat transfer coefficients, the heat exchanger was divided into nine control volumes along length $L_{h x}$, and arranged as in Figure 2. The thermocouples on the outer-tube wall measure the annulus fluid temperature. The local annulus heat transfer coefficient is defined as:

$$
h_{L M T D, C V, j}=\frac{\dot{Q}_{o, C V, j}}{A_{s, C V, j} \Delta T_{L M T D, C V, j}}
$$

With $A_{s, C V, j}$ the wall surface area for each control volume defined as:

$$
A_{s, C V, j}=\pi D_{1} L_{h x, C V, j}
$$

$\Delta T_{L M T D, C V, j}$ is calculated for a heated annulus as:

$$
\Delta T_{L M T D, C V, j}=\frac{T_{o i, C V, j}-T_{o o, C V, j}}{\ln \left[\left(T_{i w, C V, j}-T_{o o, C V, j}\right) /\left(T_{i w, C V, j}-T_{o i, C V, j}\right)\right]}
$$

Here the subscript $C V$ refers to the associated local property of control volume $j$, where $j=1 \ldots 9$. The annular inlet and outlet temperatures are obtained from temperatures measured on the outer-tube wall:

$$
T_{o i, C V, j}=T_{o, j-1}
$$




$$
T_{o o, C V, j}=T_{o, j}
$$

Control volumes one and nine located at the annulus inlet and outlet had the following inlet and outlet temperatures:

$$
\begin{aligned}
T_{o i, C V, 1} & =T_{o i} \\
T_{o o, C V, 9} & =T_{o o}
\end{aligned}
$$

The inner-wall temperature was determined by the average of the two thermocouples located at each measurement station:

$$
T_{i w, C V, j}=\frac{\left(T_{i, j, 1}+T_{i, j, 2}\right)}{2}
$$

Local fluid properties were calculated at the control volume bulk temperature:

$$
T_{b, C V}=\frac{T_{o i, C V, j}+T_{o o, C V, j}}{2}
$$

The annulus rate of heat transfer for each of the control volumes were determined by:

$$
\dot{Q}_{o, C V, j}=\dot{m}_{o, C V, j} C_{p, o, C V, j}\left(T_{o i, C V, j}-T_{o o, C V, j}\right)
$$

The dimensionless local Nusselt number for the annulus is defined as:

$$
N u_{D h, L M T D, C V, j}=\frac{h_{L M T D, C V, j} D_{h}}{k_{C V, j}}
$$

Local Reynolds numbers were calculated for each control volume with:

$$
R e_{o, C V, j}=\frac{\dot{m}_{o, C V, j} D_{h}}{\mu_{o, C V, j} A_{o}}
$$

Where $\dot{m}_{o, C V, j}$ are equal for all control volumes, and $\mu_{o, C V, j}$ is calculated at $T_{b, C V}$. 


\section{Friction factor}

The pressure drop across the annulus was measured using differential pressure transducers.

The annulus friction factors were calculated directly from the measured pressure drop with:

$$
f=\frac{2 D_{h} \Delta p}{\rho L_{d p} V^{2}}
$$

Where $\Delta p$ is the measured pressure drop of the fluid along length $L_{d p}$ of the annulus, and $V$ is the annulus fluid velocity.

\section{Colburn j-factor}

The annulus fluid temperatures for the cooled annulus were higher than those for a heated annulus. This resulted in the cooled annulus having lower Prandtl numbers than those of the heated annulus. The effect of the different Prandtl numbers was noticeable in the larger Nusselt numbers that were obtained for theheated annulus. To remove the effects of the Prandtl number, the Colburn $j$-factors were calculated as:

$$
j=\frac{N u_{D h, W P}}{\operatorname{Pr}_{o}{ }^{2 / 3} R e_{D h}}
$$

In calculating the Colburn $j$-factor, the mean Nusselt numbers obtained from the modified Wilson plot method were used. 


\section{RESULTS}

The four annular diameter ratios that were tested showed that both the heat transfer coefficients and friction factors depend on the direction of heat flux at the inner wall, as well as the annular diameter ratio.

\section{Mean Nusselt Number}

Mean experimental Nusselt numbers determined using the linear and non-linear regression schemes, and the LMTD method for the heat exchanger with $a=0.593$ are shown in Figure 6 and Figure 7 for a heated and a cooled annulus respectively. Figure 6 and Figure 7 also include the predictions of some of the correlations given in Table 1.

For a cooled annulus, close agreement was found to exist between the results obtained with the linear and non-linear regression methods. The correlations in Table 1 seem to under predict these. The mean LMTD results agree well with the linear and non-linear regression results for annular Reynolds numbers lower than 20 000. For annular Reynolds numbers higher than this, a scatter in the LMTD results is observed. On closer inspection, it is found that this scatter is directly linked to the spectrum of inner Reynolds numbers used. The mean LMTD data points on the lower edge of the scatter band in Figure 6 corresponded to test conditions at the lowest inner-tube Reynolds number, while the mean LMTD points at the upper edge of the scatter band corresponded to test conditions at the highest inner-tube Reynolds number. The differences between the regression method results and the Dirker and Meyer [2] and Gnielinski [3] correlations were up to $10 \%$.

For a heated annulus, it was observed that there is a close agreement between the mean Nusselt numbers obtained via the linear regression, non-linear regression and the LMTD methods for almost all annular Reynolds numbers tested. The deviation of the LMTD-based Nusselt numbers (as was the case with a cooled annulus) could not be verified for the heated 
case due to a smaller range of annular Reynolds numbers under consideration. For heating, the differences between the regression method results and the Dirker and Meyer [2] and Gnielinski [3] correlations were up to $15 \%$ and $8 \%$ respectively.

The differences in Nusselt numbers of this study and those obtained from the correlations of Gnielinski [3] and Dirker and Meyer [2] may be attributed to the construction methods of the test sections. The thermocouple leads in this study were fed through the inner tube. This may have influenced the inner tube heat transfer characteristics, thus affecting the annulus heat transfer characteristics. The concentricity spacers occupied $3 \%$ of the outer tube surface area. The flow characteristics in the vicinity of these concentricity spacers would be affected thus altering the heat transfer characteristics in the annulus.

Similar analyses were performed on other heat exchanger test sections with $a=0.483$, $a=0.579$ and $a=0.712$. Similar trends were obtained for all the annular diameter ratios tested. Figure 8 and Figure 9, for a cooled and heated annulus respectively, show the effect of altering the annular diameter ratio on the mean Nusselt number for specific Reynolds numbers in the annulus and inner tube. The trends observed in Figure 8 and Figure 9 were also seen for other combinations of Reynolds numbers. A heated annulus has a linearly decreasing Nusselt number with an increasing annular diameter ratio. For a cooled annulus, a maximum Nusselt number is seen in the mid-range of annular diameter ratios, which decreases as the annular diameter ratio moves from the mid-range. Due to the large scatter in the LMTD results, an averaging scheme was used through the points to provide an accurate data point at the respective Reynolds numbers.

\section{Local Nusselt Numbers}

The measured inner-tube and outer-tube wall temperatures are shown in Figure 10 a) and b) for a cooled and heated annulus respectively. All combinations of inner-tube and annular 
Reynolds numbers showed similar trends in both the inner-tube and outer-tube wall temperatures. The local heat transfer is highly sensitive to wall temperature errors on both the inner-tube wall and outer tube wall. A sensitivity analysis showed that a measurement error of $1{ }^{\circ} \mathrm{C}$ on the inner tube wall resulted in a local Nusselt number error in excess of $160 \%$. By implementing a second-order polynomial fit through the measured wall temperatures, these errors were minimized by evening out the measured wall temperature profile. The polynomial curve fits differed from the measured temperatures by a maximum of $0.66^{\circ} \mathrm{C}$. Included in Figure 10 are the polynomial fits through the measured wall temperatures, as well as the annulus inlet and outlet temperatures. It can be seen that these polynomial functions captured the data well. Using the polynomial fitted curve for the inner-tube and outer-tube wall temperatures, the local Nusselt numbers along the axial length of the heat exchanger were calculated.

Figure 11 and Figure 12 show the local Nusselt numbers along the heat exchanger length at specific local Reynolds numbers (based on the local bulk temperature) for a cooled and a heated annulus respectively. The local Nusselt number is at its highest value at the inlet and decreases along the length of the heat exchanger. The steepest drop is present directly after the inlet, whereafter the gradient gradually reduces along the length of the heat exchanger. This is attributed to the fact that the flow is thermally developing, Cengel [9] suggests thermally developed flow is obtained at a distance 10 times the hydraulic diameter. As expected, higher local Reynolds numbers resulted in higher Nusselt numbers. Similar trends were observed for all annular inner-tube Reynolds number combinations, as well as for the three other annular diameter ratios tested. 


\section{Friction Factor}

Friction factors for each heat exchanger were calculated using equation (37). Figure 13 shows the effects of altering the annular diameter ratio on friction factors for a heated and a cooled annulus with $R e_{D h}=20000$. Both a heated and a cooled annulus showed that for smalle $a$ values, the correlations of Table 2 under predict the friction factors. However, for larger $a$ values, the correlations of Jones and Leung [8] and Gnielinski [3] over predict the friction factors while the correlations of Kaneda et al. [7] and Blasius [9] under predict the friction factors. A cooled annulus showed friction factors up to $9 \%$ larger than the friction factors of a heated annulus. For both a heated and a cooled annulus, the friction factor decreased by $10 \%$ when the annular diameter ratio increased from 0.483 to 0.712 . It can be seen that the friction factors of this study show a significantly larger dependence on the annular diameter ratio. Ntuli et al. [14] performed similar tests as reported on here for an annular diameter ratio of 0.355. The friction factor for a heated annulus from their results is included in Figure 13.

\section{Colburn j-factor}

Large differences (up to 35\%) in mean Nusselt numbers between a heated and a cooled annulus were obtained for all the test sections. As a result, the Colburn $\mathrm{j}$-factors were calculated to investigate the effect of the Prandtl number on the heat transfer. The Colburn $j$-factors for a heated and a cooled annulus are shown on a logarithmic scale in Figure 14.

The average percentage difference for the Colburn $j$-factor between a heated and a cooled annulus is $2.6 \%$. This is small in comparison with the $35 \%$ difference between the Nusselt numbers for a heated and a cooled annulus. This indicates that by removing the effects of the Prandtl number, there was a closer agreement in the results of a heated and a cooled annulus. The larger Nusselt numbers obtained for a heated annulus were thus a result of the larger 
Prandtl numbers. Similar trends were also observed for the other annular diameter ratios tested.

The experimental friction factors were also plotted on the same set of axis as the Colburn $j$-factors in Figure 14. A relationship is seen to exist between the Colburn $j$-factors and friction factors. The ratio of the Colburn $j$-factors to the experimental friction factors is

plotted in Figure 15. Polynomial curves were fitted through the points in Figure 15 for all annular diameter ratios and for both a heated and a cooled annulus. The polynomial curves are of the form:

$$
\frac{j}{f}=\tau=C_{1} R e_{D h}^{2}+C_{2} R e_{D h}+C_{3}
$$

The constants $C_{1}, C_{2}$ and $C_{3}$ are provided in Table 6 .

Figure 15 shows that this ratio is dependent on the annular diameter ratio, with the larger annular diameter ratio producing a larger $\tau$. This is seen for both a heated and a cooled annulus. For $R e_{D h}>45000, \tau$ approaches a constant value and no longer depends on $R e_{D h}$. This observation is only for the cooled annulus as the $R e_{D h}$ for the heated annulus was limited to 25000 .

\section{CONCLUSIONS}

Four heat exchangers, each with a different annular diameter ratio, were tested for two different heat flux directions across the wall, namely a heated and a cooled annulus. The direction of heat flux across the wall affected both the annulus heat transfer and friction factors. Three methods of calculating the mean Nusselt numbers were used. These were the mean LMTD method, the modified Wilson plot linear regression and a non-linear regression. 
The linear and non-linear regressions produced similar results and were both larger than existing correlations. The mean LMTD method agreed with the linear and non-linear regression methods for lower annular Reynolds numbers. Larger Reynolds numbers were tested with a cooled annulus only, and it was seen that the mean LMTD method produced Nusselt numbers that were lower than those for the linear and non-linear regressions. The linear and non-linear regression analysis produced Nusselt numbers that were on average $15 \%$ and $10 \%$ larger than recent correlations for a heated and a cooled annulus respectively. Friction factors for a heated annulus were on average $9 \%$ lower than for a cooled annulus.

A heated annulus showed Nusselt numbers that were on average 35\% larger than for a cooled annulus. This difference was mainly attributed to the effect of the Prandtl number on the Nusselt numbers. To investigate the effects of the Prandtl number, the Colburn $j$-factors were calculated. A difference in the region of $2.6 \%$ on average in the Colburn $j$-factor between a heated and a cooled annulus indicated that by removing the effects of the Prandtl number, a heated and a cooled annulus produce similar heat transfer results

Altering the annular diameter ratio affected the annulus Nusselt numbers and friction factors. A heated annulus showed a decrease in Nusselt number with an increase in annular diameter ratio. A cooled annulus showed that a maximum Nusselt number was reached in the mid-range of the annular diameter ratios tested and decreased as the annular diameter moved away from the mid-range annular diameter ratio.

The annular diameter ratio has a greater influence on the friction factor than the existing correlations predict. The friction factors for a heated and a cooled annulus decreased by $10 \%$ with an increase in annular diameter ratio from 0.483 to 0.712 . 


\section{Further Research}

Similar test sections to those used in this study should be investigated further to provide clarity as to why the Nusselt numbers are larger to those obtained from the correlations of previous researchers. A larger range of Reynolds numbers for a heated annulus could be investigated to allow a comparison to a cooled annulus at high Reynolds numbers. The annulus inlet temperatures in this study were held constant. Different annulus inlet temperatures could also be investigated to observe, in more detail, the effects of the Prandtl number. 


\section{Nomenclature}

$a$

$A_{s}$

$A_{o}$

$C_{1}$

$C_{2}$

$C_{3}$

$C_{i}$

$C_{o}$

$C_{p}$

$D_{h}$

$D_{i}$

$D_{o}$

$D_{1}$

$e b$

$f$

$F_{a n n}$

$h$

$j$

$k$

K

$L_{d p}$ annular diameter ratio, dimensionless

surface area, $\mathrm{m}^{2}$

cross-sectional area of annulus, $\mathrm{m}^{2}$

coefficient in equation (39), dimensionless, constant

coefficient in equation (39), dimensionless, constant

coefficient in equation (39), dimensionless, constant

inner-tube correlation coefficient, dimensionless

outer-tube correlation coefficient, dimensionless

specific heat, $\mathrm{J} / \mathrm{kgK}$

hydraulic diameter, $\mathrm{m}$

inner diameter of inner tube, $\mathrm{m}$

inner diameter of outer tube, $\mathrm{m}$

outer diameter of inner tube, $\mathrm{m}$

energy balance, $\%$

friction factor, dimensionless

factor taking into account the dependence on $a$ (annular

diameter ratio), dimensionless

convective heat transfer coefficient, $\mathrm{W} / \mathrm{m}^{2} \mathrm{~K}$

Colburn $j$-factor, dimensionless

thermal conductivity, $\mathrm{W} / \mathrm{mK}$

factor to take into account the temperature dependence in

equation (2) of fluid properties, dimensionless

pressure drop length, $\mathrm{m}$ 


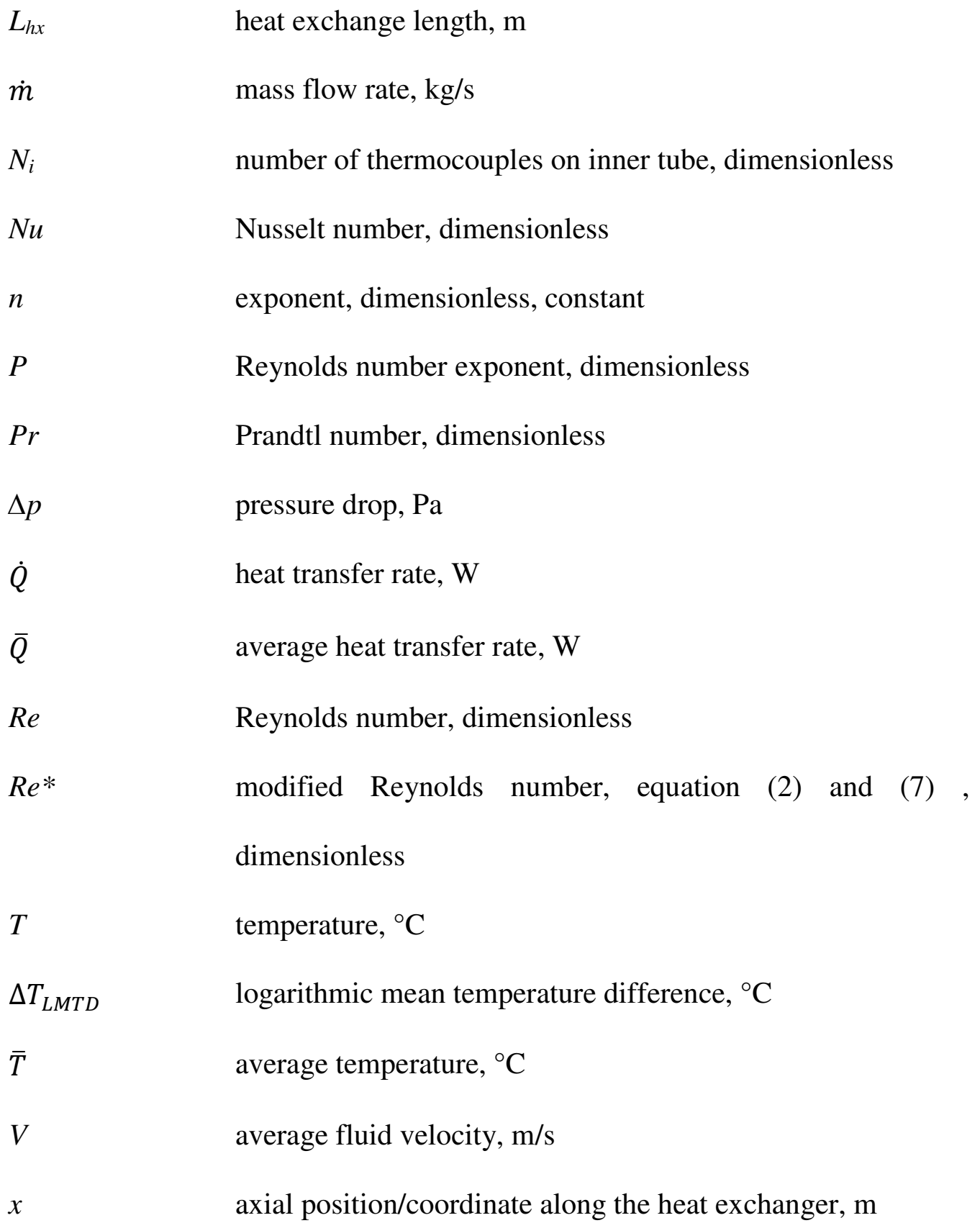

$\begin{array}{ll}\mu & \text { kinematic viscosity, } \mathrm{m}^{2} / \mathrm{s} \\ \rho & \text { density, } \mathrm{kg} / \mathrm{m}^{3} \\ \tau & \text { ratio of } j \text { and } f, \text { dimensionless } \\ \varphi & \text { factor in equation (2), dimensionless }\end{array}$




\section{Subscripts}

\begin{tabular}{|c|c|}
\hline$C V$ & control volume \\
\hline 1 & inner-tube outer wall \\
\hline$b$ & bulk property \\
\hline$D h$ & based on hydraulic diameter \\
\hline$i$ & inner tube \\
\hline$i i$ & inner-tube inlet \\
\hline io & inner-tube outlet \\
\hline$j$ & index number \\
\hline LMTD & $\begin{array}{l}\text { based on the logarithmic mean temperature difference } \\
\text { analysis }\end{array}$ \\
\hline local & local property \\
\hline$o$ & annulus \\
\hline$o i$ & annulus inlet \\
\hline$o o$ & annulus outlet \\
\hline$i w$ & inner tube wall \\
\hline$W P$ & referring to the modified Wilson plot method \\
\hline
\end{tabular}


[1] Gnielinski, V., VDI-Heat Atlas, Section GD,VDI-Verlag, 1993.

[2] Dirker, J., and Meyer, J.P., Convection Heat Transfer in Concentric Annuli, Experimental Heat and Mass Transfer, vol. 17, pp. 19-29, 2004.

[3] Gnielinski, V., Heat Transfer Coefficients for Turbulent Flow in Concentric Annular Ducts, Heat Transfer Engineering, vol. 30, pp. 431-436, 2009.

[4] Lu, G., and Wang, J., Experimental Investigation on Heat Transfer Characteristics of Water Flow in a Narrow Annulus, Applied Thermal Engineering, vol. 28, pp. 8-13, 2008.

[5] Swamee, P.K., Aggarwal, N., and Aggarwal, V., Optimum Design of Double Pipe Heat Exchangers, International Journal of Heat and Mass Transfer, vol. 51, pp. 22602266, 2008.

[6] Dittus, F.W., and Boelter, L.M.K., Publications on Engineering, vol. 2, p. 443, University of California, Berkeley, 1930.

[7] Kaneda, M., Yu, B., Ozoe, H., and Churchill, S.W., The Characteristics of Turbulent Flow and Convection in Concentric Circular Annuli, International Journal of Heat and Mass Transfer, vol. 46, pp. 5045-5057, 2003.

[8] Jones, O.C., and Leung, J.C.M., An Inprovement in the Calculation of Turbulent Friction in Smooth Concentric Annuli, Journal of Fluids Engineering, vol. 103, pp. 615-623, 1981.

[9] Cengel, Y. A., Heat and Mass Transfer: A Practical Approach, $3^{\text {rd }}$ ed., pp. 451 - 500, McGraw-Hill, 2006. 
[10] Popiel, C.O., and Wojtkowiak, J., Simple Formulas for Thermophysical Properties of Liquid Water for Heat Transfer Calculations, Heat Transfer Engineering, vol. 19, no. 3, pp. $87-101,1998$.

[11] Kline, S., and McClintock, F., Describing Uncertainties in Single-Sample Experiments, Mechanical Engineering, vol. 75, pp. 2-8, 1969.

[12] Briggs, D.E., and Young, E.H., Modified Wilson Plot Technique for Obtaining Heat Transfer Correlations for Shell and Tube Heat Exchangers, Chemical Engineering Progress Symposium, vol. 65, pp. 35-45, 1969.

[13] Khartabil, H.F., and Christensen, R.N., An Improved Scheme for Determining Heat Transfer Correlations From Heat Exchanger Regression Models with Three Unknowns, Experimental Thermal and Fluid Science, vol. 5, pp. 808-819, 1992.

[14] Ntuli, M.P., Dirker, J., and Meyer, J.P., Heat Transfer and Pressure Drop Coefficients for Turbulent Flow in Concentric Annular Ducts, 19th International Congress of Chemical and Process Engineering, Prague, 2010. 


\section{Table Captions}

Table 1: Existing Nusselt number correlations for annular passages.

Table 2: Existing friction factor correlations for annular ducts.

Table 3: Uncertainties of instrumentation.

Table 4: Uncertainties of measured parameters.

Table 5: Dimensions of test sections (refer to Figure 2 and Figure 3).

Table 6: Constants $C_{1}, C_{2}$ and $C_{3}$ for the polynomial curves fitted to the ratio of Colburn $j$ factors to experimental friction factors. 
Table 1: Existing Nusselt number correlations for annular passages.

\begin{tabular}{|c|c|c|c|c|c|}
\hline Author(s) & Correlation & Equation & $\begin{array}{l}\text { Diameter ratio } \\
\text { range }(a)\end{array}$ & $\begin{array}{l}\text { Reynolds } \\
\text { number } \\
\text { range }\left(R e_{D h}\right)\end{array}$ & $\begin{array}{l}\text { Working } \\
\text { fluid }\end{array}$ \\
\hline $\begin{array}{l}\text { Dirker and } \\
\text { Meyer [2] }\end{array}$ & $\begin{array}{l}N u_{D h}=C_{o} \operatorname{Re}_{D_{h}}^{P} \operatorname{Pr}^{1 / 3}\left(\frac{\mu_{o}}{\mu_{i w}}\right)^{0.14} \\
P=1.013 e^{-0.067 / a} \\
C_{o}=\frac{0.003 a^{1.86}}{0.063 a^{-3}-0.0674 a^{-2}+2.225 / a-1.157}\end{array}$ & (1) & $0.3125-0.588$ & $\begin{array}{l}4000- \\
30000\end{array}$ & Water \\
\hline Gnielinski[3] & $\begin{array}{l}N u_{D h}=\frac{(f / 8) R e_{D h} P r_{o}}{\varphi+12.7 \sqrt{f / 8}\left(P r_{o}^{2 / 3}-1\right)}\left[1+\left(\frac{D_{h}}{L_{h x}}\right)^{2 / 3}\right] F_{a n n} K \\
\varphi=1.07+\frac{900}{R e_{D h}}-\frac{0.63}{\left(1+10 P r_{o}\right)} \\
K=\left(\frac{P r_{o}}{P r_{i w}}\right)^{0.11} \quad \text { for liquids } \\
K=\left(\frac{T_{b}}{T_{i w}}\right)^{n} \quad \text { for gases } \quad \text { with } n=0 \text { for cooling } \\
F_{a n n}=0.75 a^{-0.17} \quad n=0.45 \text { for } 0.5<\frac{T_{b}}{T_{i w}}<1.0 \\
f=\left(1.8 \log _{10} R e^{*}-1.5\right)^{-2} \\
R e^{*}=R e_{D h} \frac{\left(1+a^{2}\right) \ln a+\left(1-a^{2}\right)}{(1-a)^{2} \ln a}\end{array}$ & (2) & Not specified & Not specified & All media \\
\hline $\begin{array}{l}\text { Lu and } \\
\text { Wang [4] }\end{array}$ & $N u_{D h}=0.0022 R e_{D h}^{1.09} P r_{o}^{0.4}$ & (3) & 0.6911 & $>3000$ & Water \\
\hline $\begin{array}{l}\text { Swameeet al. } \\
{[5]}\end{array}$ & $N u_{D h}=\frac{0.027}{(1+1 / a)^{0.2}} \operatorname{Re}_{D h}^{0.8} \operatorname{Pr}_{o}^{1 / 3}\left(\frac{\mu_{o}}{\mu_{i w}}\right)^{0.14}$ & (4) & Not specified & Not specified & Not specified \\
\hline $\begin{array}{l}\text { Dittus and } \\
\text { Boelter[6] }\end{array}$ & $\begin{array}{ll}N u_{D h}=0.023 R e_{D_{h}}^{0.8} \operatorname{Pr}_{o}^{n} & n=0.3 \text { for cooling } \\
& n=0.4 \text { for heating }\end{array}$ & (5) & Not specified & $>10000$ & Not specified \\
\hline
\end{tabular}


Table 2: Existing friction factor correlations for annular ducts.

\begin{tabular}{|c|c|c|c|c|c|}
\hline Author(s) & Correlation & Equation & $\begin{array}{l}\text { Diameter ratio } \\
\text { range }(a)\end{array}$ & $\begin{array}{l}\text { Reynolds } \\
\text { Number } \\
\text { range }\left(R e_{\mathrm{Dh}}\right)\end{array}$ & $\begin{array}{l}\text { Working } \\
\text { fluid }\end{array}$ \\
\hline $\begin{array}{l}\text { Kanedaet } \\
\text { al. }[7]\end{array}$ & $\frac{f}{8}=\left[1.61+\frac{1}{0.436} \ln \left(\frac{R e_{D h}}{\sqrt{8 / f}}\right)-\frac{550}{R e_{D h} \sqrt{f / 8}}\right]^{-2}$ & (6) & $0.0-1.0$ & $>10000$ & Not specified \\
\hline $\begin{array}{l}\text { Jones and } \\
\text { Leung }[8]\end{array}$ & $\begin{array}{l}\frac{1}{\sqrt{f}}=2 \log _{10} R e^{*} \sqrt{f}-0.8 \\
R e^{*}=R e_{D h} \frac{\left(1+a^{2}\right) \ln a+\left(1-a^{2}\right)}{(1-a)^{2} \ln a}\end{array}$ & (7) & $0.0-1.0$ & $\begin{array}{lrl}10 & 000 & - \\
1,000,000 & \end{array}$ & $\begin{array}{l}\text { Based on } \\
\text { other authors } \\
\text { data. }\end{array}$ \\
\hline Gnielinski[3] & $\begin{array}{l}\frac{1}{\sqrt{f}}=1.8 \log _{10} R e^{*}-1.5 \\
R e^{*}=R e_{D h} \frac{\left(1+a^{2}\right) \ln a+\left(1-a^{2}\right)}{(1-a)^{2} \ln a}\end{array}$ & (8) & Not specified & Not specified & All media \\
\hline Blasius[9] & $f=0.3164 R e_{D h}^{-0.25}$ & (9) & Not specified & Not specified & All media \\
\hline
\end{tabular}


Table 3: Uncertainties of instrumentation.

\begin{tabular}{llll}
\hline Item & Instrument & Range & Uncertainty \\
\hline & Thermocouple & $-200-350^{\circ} \mathrm{C}$ & $\pm 0.1^{\circ} \mathrm{C}$ \\
$6(\mathrm{a})$ & Flow meter & $0.015-0.603 \mathrm{~kg} / \mathrm{s}$ & $\pm 0.1 \%^{\mathbf{r}}$ \\
$6(\mathrm{~b})$ & Flow meter & $0.047-1.883 \mathrm{~kg} / \mathrm{s}$ & $\pm 0.1 \%^{\mathbf{r}}$ \\
9 & Differential & pressure & \\
& transducers & $0-21 \mathrm{kPa}$ & $\pm 2.0 \%^{\mathrm{fs}}$ \\
& & $0-35 \mathrm{kPa}$ & $\pm 2.2 \%^{\mathrm{fs}}$ \\
& & $0-140 \mathrm{kPa}$ & $\pm 2.6 \%^{\text {fs }}$
\end{tabular}

fs: Percentage of full-scale value.

r: Percentage of reading. 
Table 4: Uncertainties of measured parameters.

\begin{tabular}{lll}
\hline Parameter & Mean $(\%)$ & Local $(\%)$ \\
\hline$N u_{D h, L M T D}$ & \pm 2.00 & \pm 7.49 \\
$h_{L M T D}$ & \pm 0.09 & \pm 6.97 \\
$R e_{D h}$ & \pm 1.02 & \pm 1.02 \\
$j$ & \pm 2.70 & Not measured \\
$f$ & \pm 1.57 & Not Measured
\end{tabular}


Table 5: Dimensions of test sections (refer to Figure 2 and Figure 3).

\begin{tabular}{llllllll}
\hline Heat Exchanger & $\boldsymbol{D}_{\boldsymbol{i}}(\mathbf{m m})$ & $\boldsymbol{D}_{\boldsymbol{l}}(\mathbf{m m})$ & $\boldsymbol{D}_{\boldsymbol{o}}(\mathbf{m m})$ & $\boldsymbol{D}_{\boldsymbol{h}}(\mathbf{m})$ & $\boldsymbol{a}(-)$ & $\boldsymbol{L}_{\boldsymbol{h x}}(\mathbf{m})$ & $\boldsymbol{L}_{d p}(\mathbf{m})$ \\
\hline $\mathbf{1}$ & 14.46 & 15.88 & 32.89 & 17.01 & 0.483 & 4.85 & 4.79 \\
$\mathbf{2}$ & 17.63 & 19.05 & 32.89 & 13.84 & 0.579 & 5.30 & 4.98 \\
$\mathbf{3}$ & 14.46 & 15.88 & 26.76 & 10.88 & 0.593 & 4.85 & 4.79 \\
$\mathbf{4}$ & 17.63 & 19.05 & 26.76 & 7.71 & 0.712 & 5.06 & 5.00 \\
\hline
\end{tabular}


Table 6: Constants $C_{1}, C_{2}$ and $C_{3}$ for the polynomial curves fitted to the ratio of Colburn $\boldsymbol{j}$-factors to experimental friction factors.

\begin{tabular}{l|ccc|ccc}
\hline $\begin{array}{c}\text { Annular diameter } \\
\text { ratio }(\boldsymbol{a})\end{array}$ & \multicolumn{3}{c|}{ Cooling } & \multicolumn{3}{c}{ Heating } \\
\hline & $\boldsymbol{C}_{\boldsymbol{1}}$ & $\boldsymbol{C}_{\boldsymbol{2}}$ & $\boldsymbol{C}_{\boldsymbol{3}}$ & $\boldsymbol{C}_{\boldsymbol{1}}$ & $\boldsymbol{C}_{\boldsymbol{2}}$ & $\boldsymbol{C}_{\boldsymbol{3}}$ \\
\hline $\mathbf{0 . 4 8 3}$ & $-5.38 \mathrm{e}-012$ & $6.05 \mathrm{e}-007$ & $6.06 \mathrm{e}-002$ & $1.14 \mathrm{e}-011$ & $2.17 \mathrm{e}-008$ & $6.49 \mathrm{e}-002$ \\
$\mathbf{0 . 5 7 9}$ & $-1.84 \mathrm{e}-011$ & $1.59 \mathrm{e}-006$ & $5.15 \mathrm{e}-002$ & $-1.42 \mathrm{e}-011$ & $1.23 \mathrm{e}-006$ & $5.32 \mathrm{e}-002$ \\
$\mathbf{0 . 5 9 3}$ & $-1.37 \mathrm{e}-011$ & $1.45 \mathrm{e}-006$ & $5.02 \mathrm{e}-002$ & $-2.80 \mathrm{e}-011$ & $1.93 \mathrm{e}-006$ & $4.50 \mathrm{e}-002$ \\
$\mathbf{0 . 7 1 2}$ & $-1.85 \mathrm{e}-011$ & $1.86 \mathrm{e}-006$ & $5.31 \mathrm{e}-002$ & $-2.72 \mathrm{e}-011$ & $1.87 \mathrm{e}-006$ & $5.0 \mathrm{e}-002$ \\
\hline
\end{tabular}




\section{Figure Captions}

Figure 1: Experimental test facility.

Figure 2: Heat exchanger separated into nine control volumes.

Figure 3: Cross-section and boundary conditions of tube-in-tube heat exchanger (not drawn to scale).

Figure 4: Attachment of thermocouples to inner-tube wall.

Figure 5: Concentricity spacers integrated into couplings.

Figure 6: Mean Nusselt numbers for a cooled annulus.

Figure 7: Mean Nusselt numbers for a heated annulus.

Figure 8: Nusselt numbers for a cooled annulus and four annular diameter ratios.

Figure 9: Nusselt numbers for a heated annulus and four annular diameter ratios.

Figure 10: Inner- and outer-wall temperature profiles for a) a cooled annulus and b) a heated annulus.

Figure 11: Nusselt numbers for various local Reynolds numbers for a cooled annulus.

Figure 12: Nusselt numbers for various local Reynolds numbers for a heated annulus.

Figure 13: Friction factors for a heated and a cooled annulus.

Figure 14: Colburn j-factors for a heated and a cooled annulus.

Figure 15: Ratio of Colburn j-factor to experimental friction factor. 


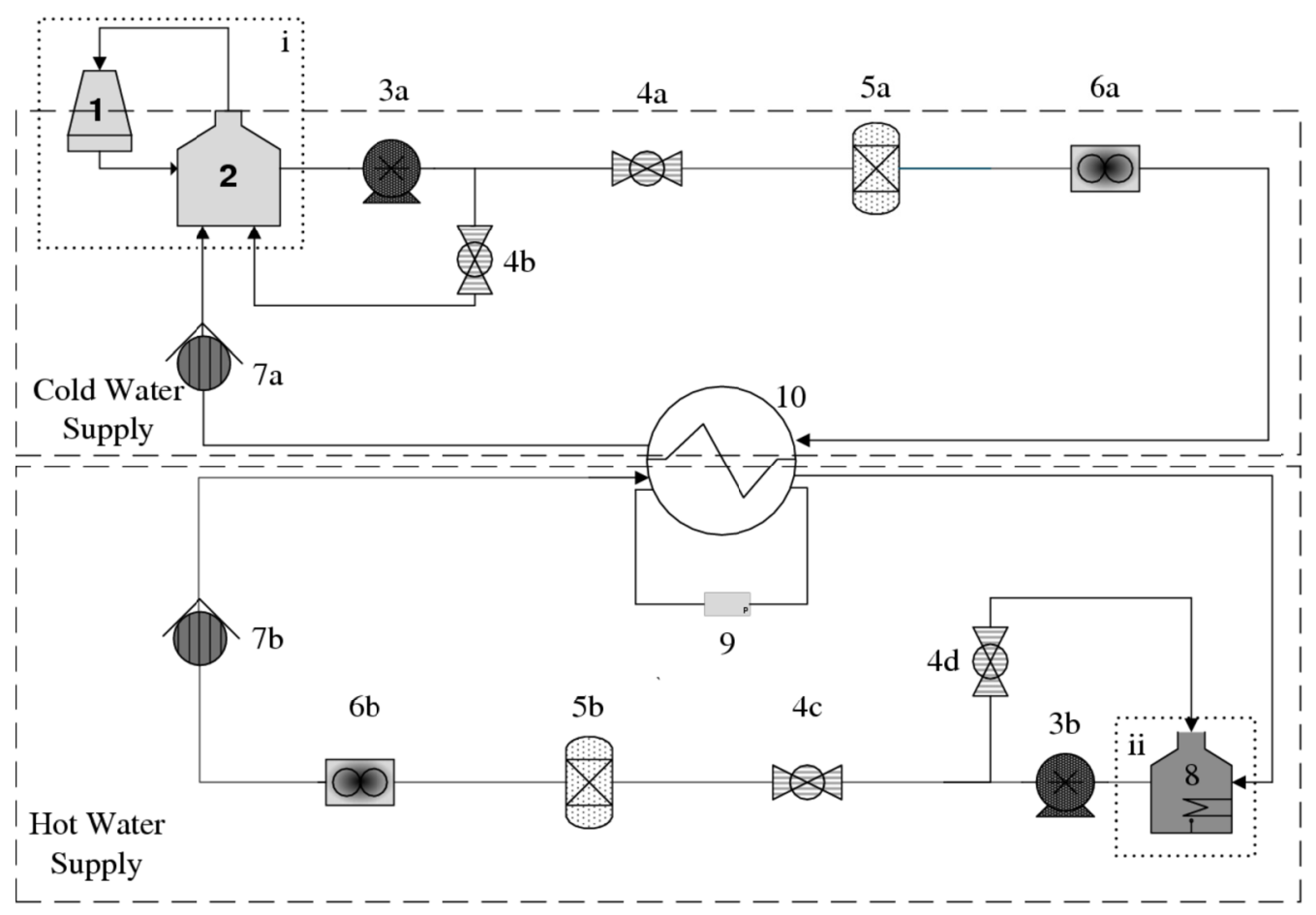

Figure 1: Experimental test facility. 


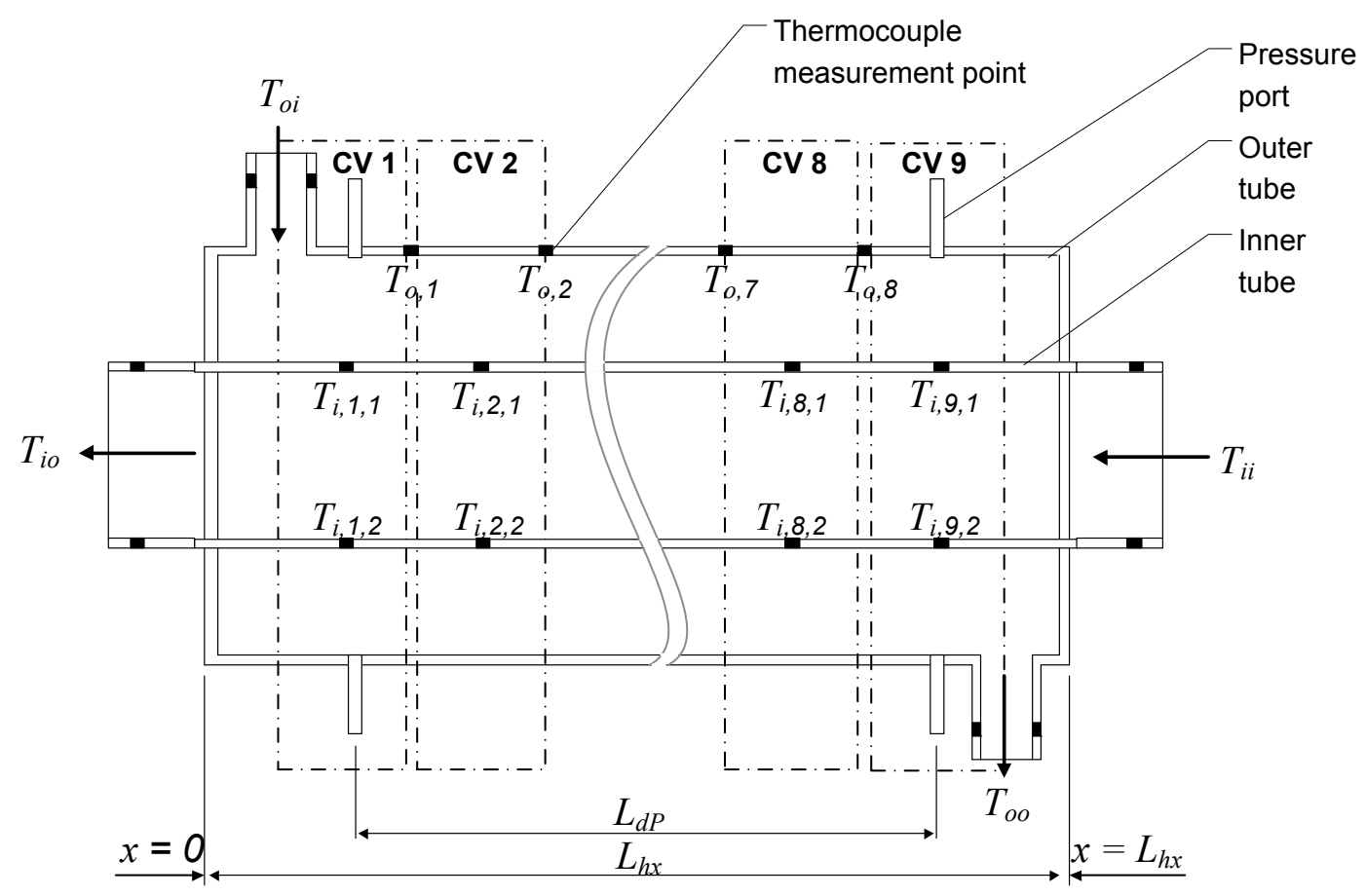

Figure 2: Heat exchanger separated into nine control volumes. 


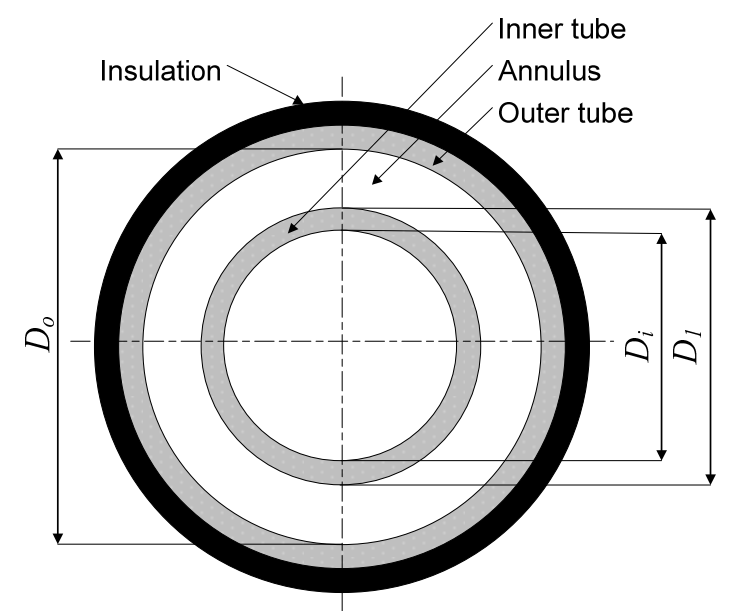

Figure 3: Cross-section and boundary conditions of tube-in-tube heat exchanger (not drawn to scale). 


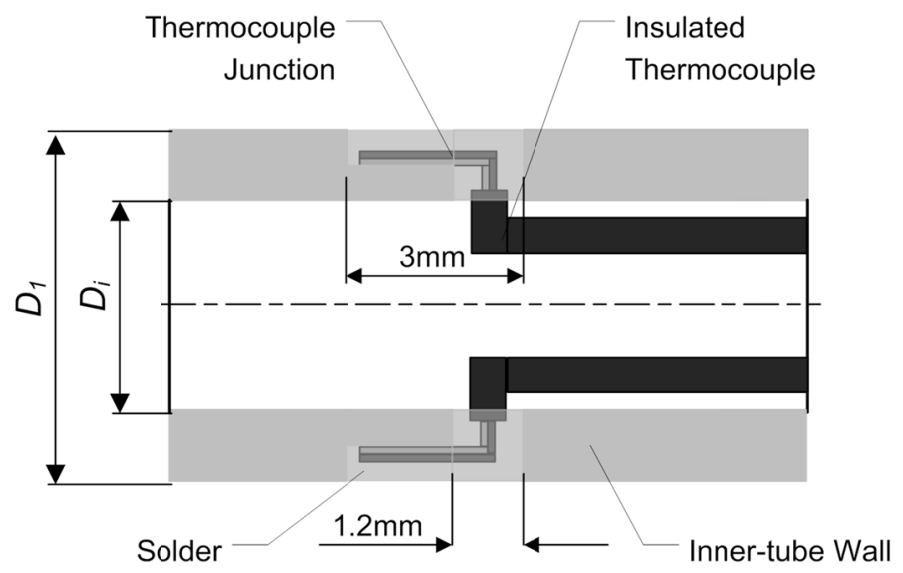

Figure 4: Attachment of thermocouples to inner-tube wall. 


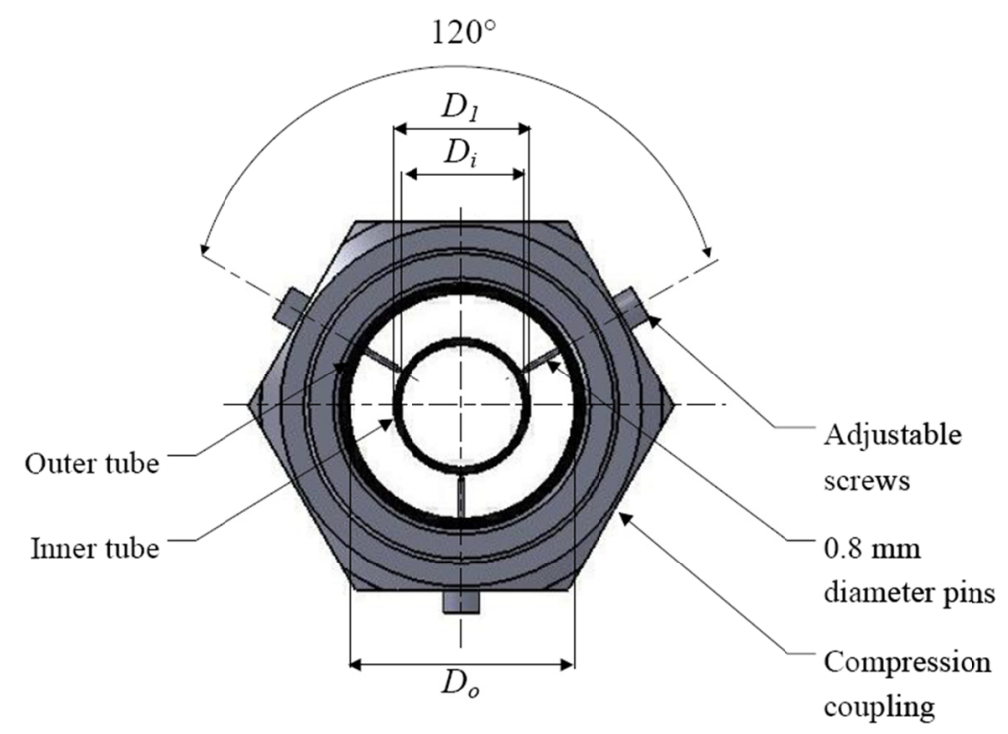

Figure 5: Concentricity spacers integrated into couplings. 


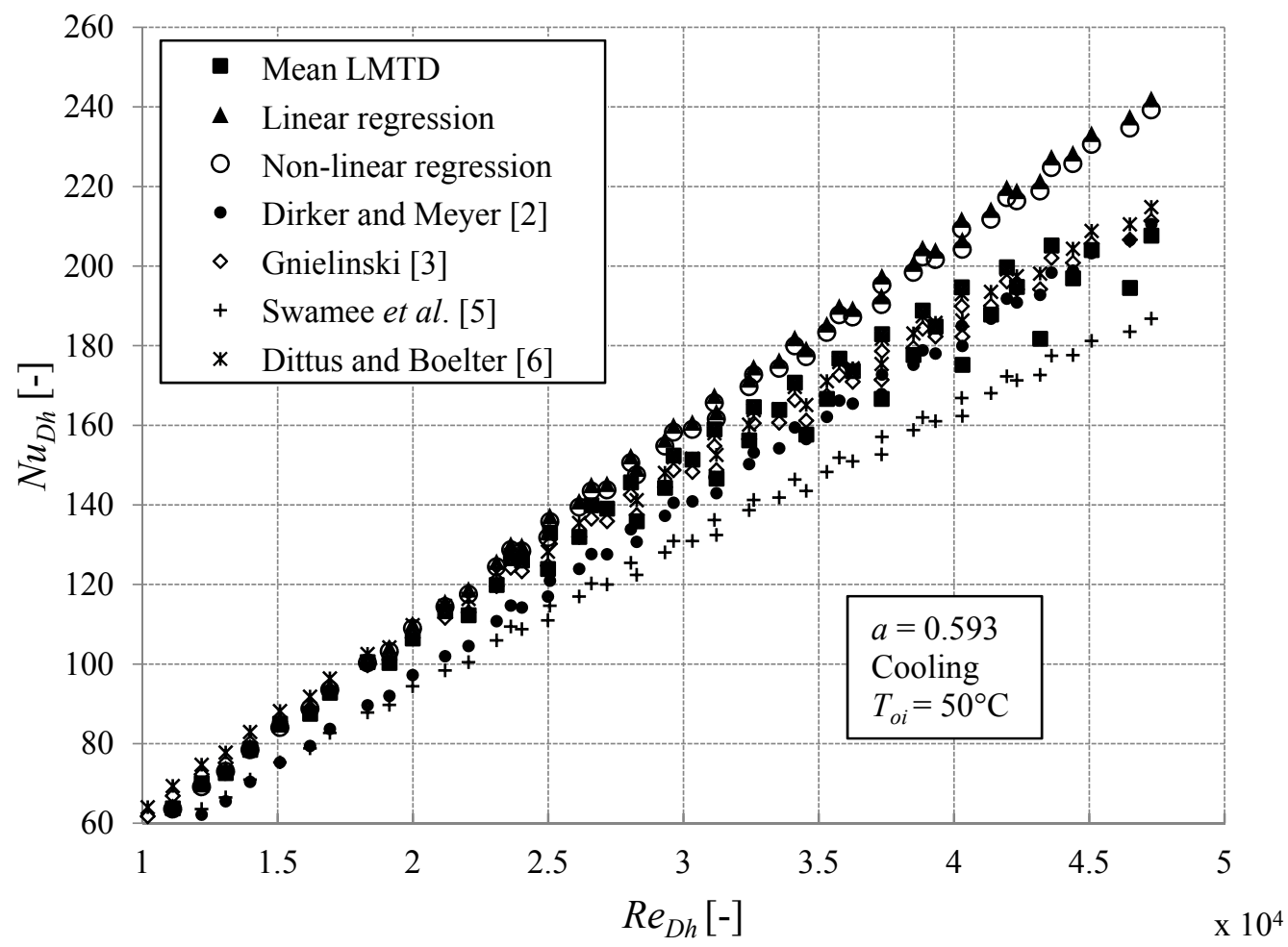

Figure 6: Mean Nusselt numbers for a cooled annulus. 


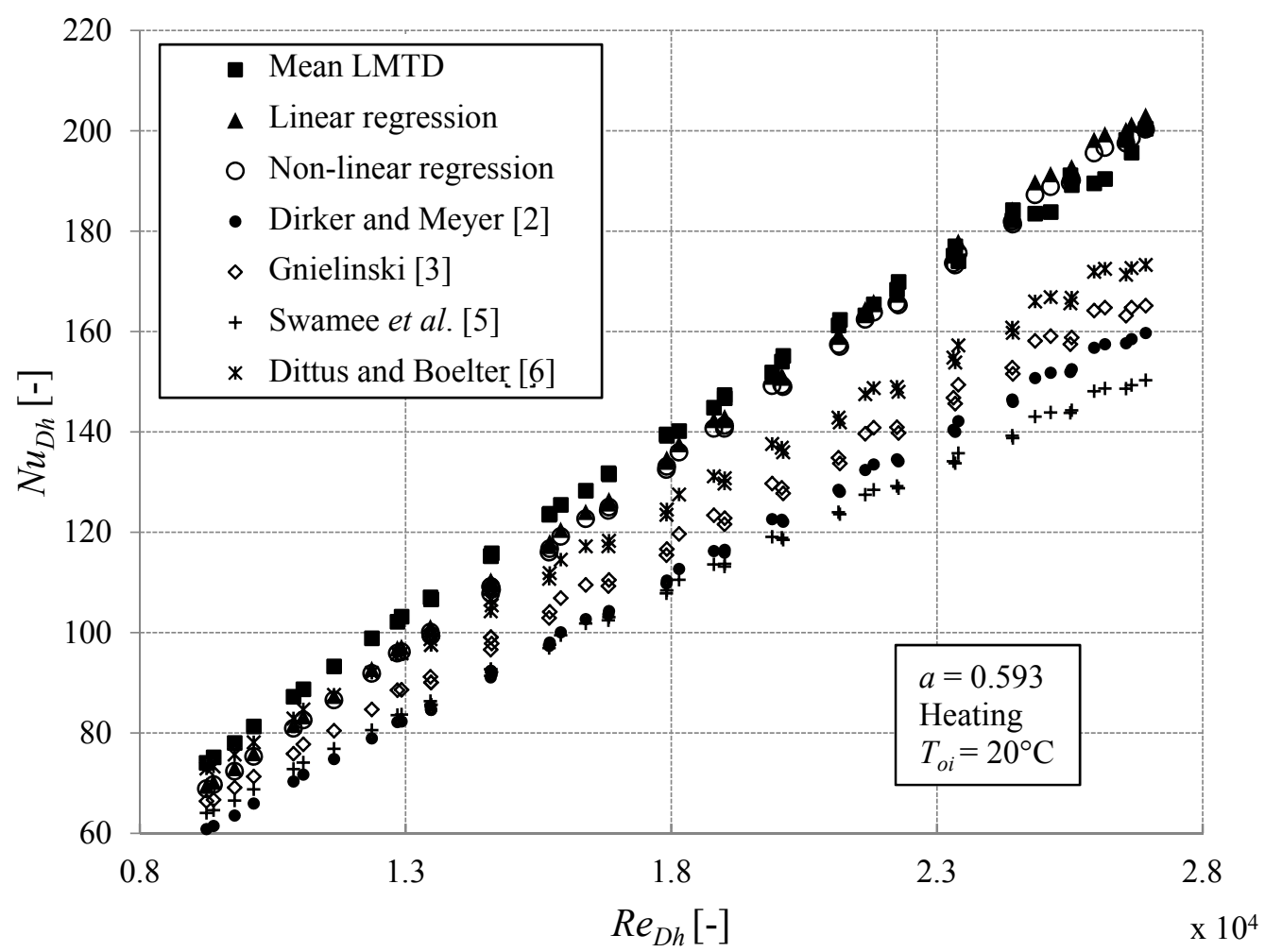

Figure 7: Mean Nusselt numbers for a heated annulus. 


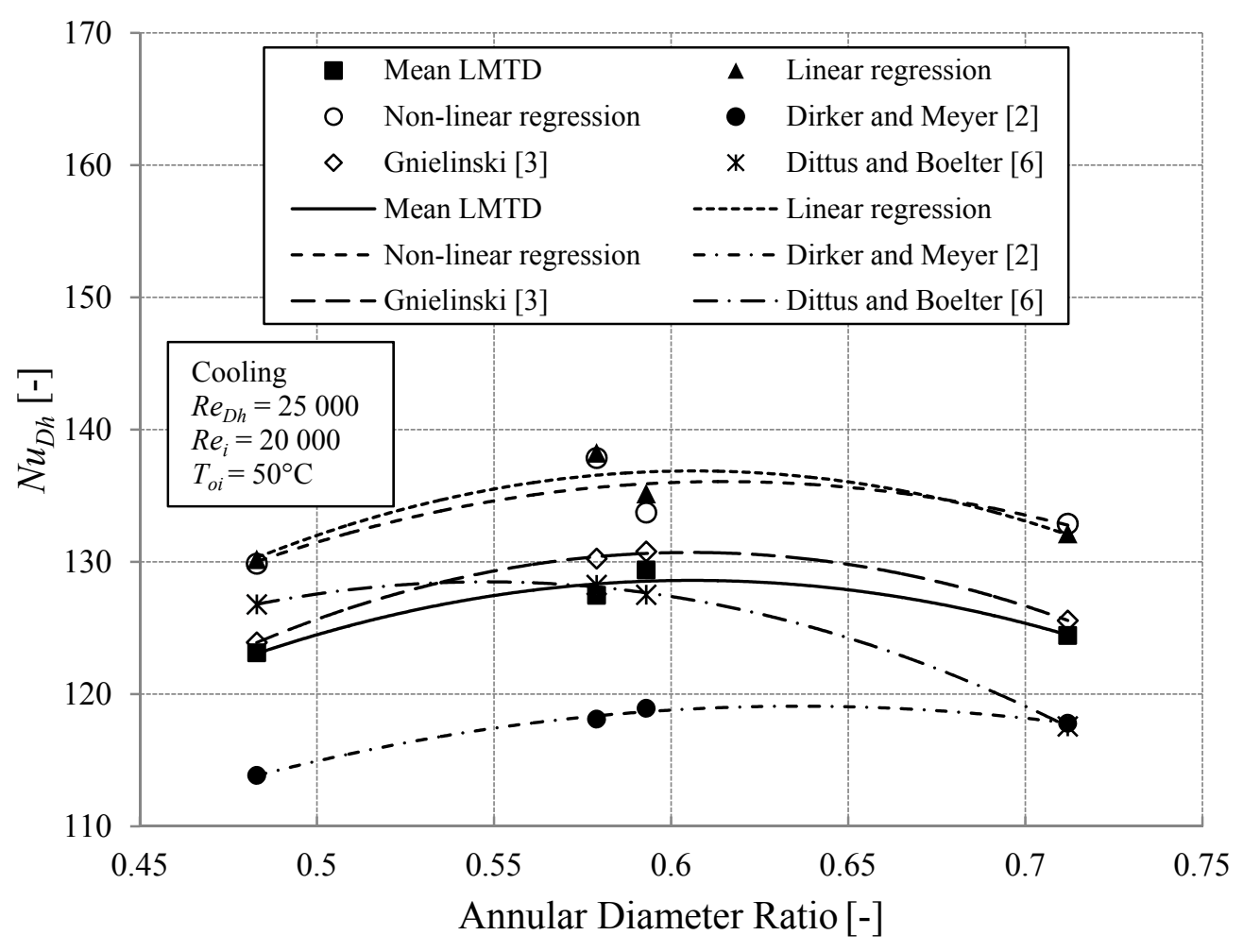

Figure 8: Nusselt numbers for a cooled annulus and four annular diameter ratios. 


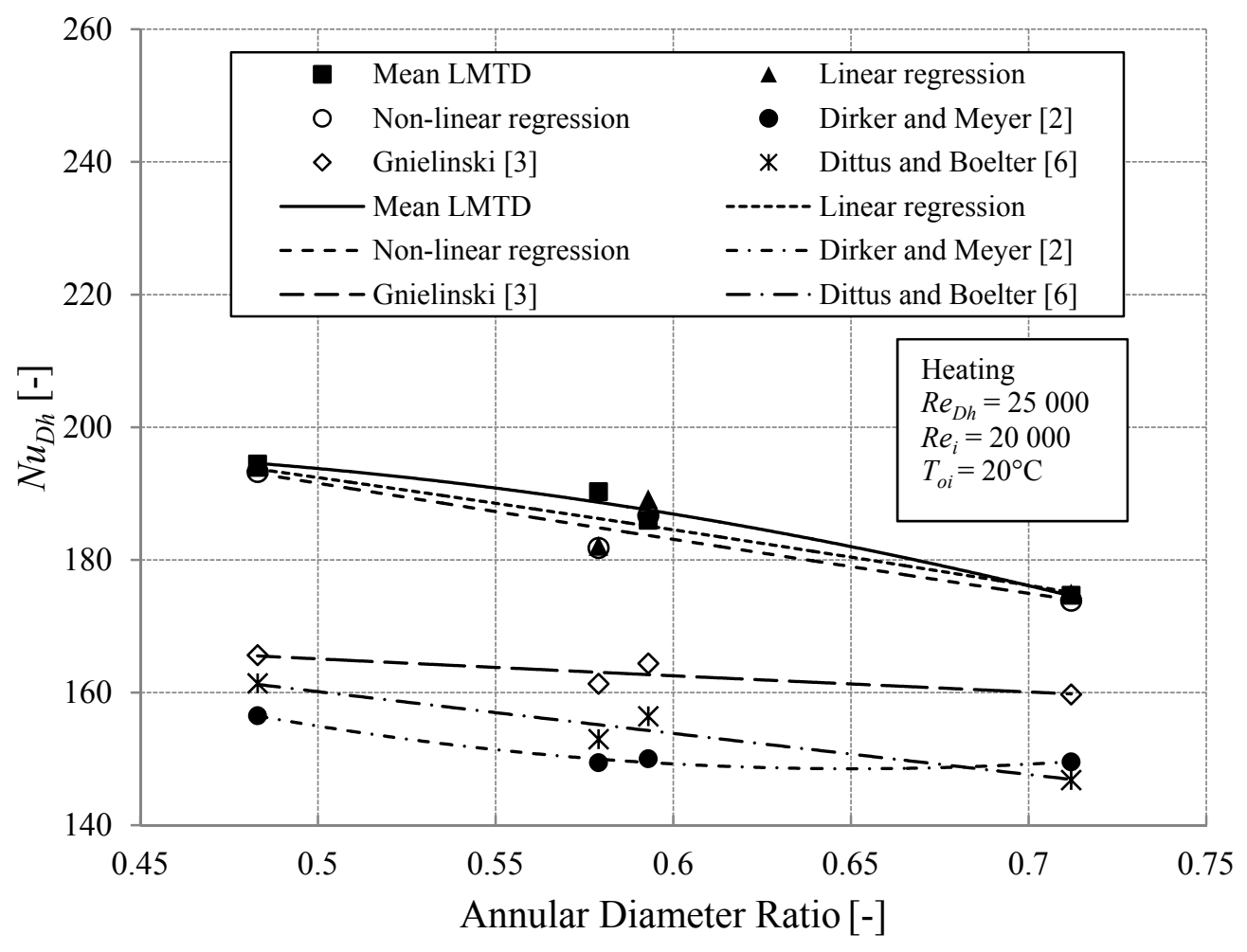

Figure 9: Nusselt numbers for a heated annulus and four annular diameter ratios. 

\ $T_{o w}$ Experimental
- $T_{i w}$ Experimental
$T_{o w}$ Curve fit $\quad--T_{i w}$ Curve fit

a)

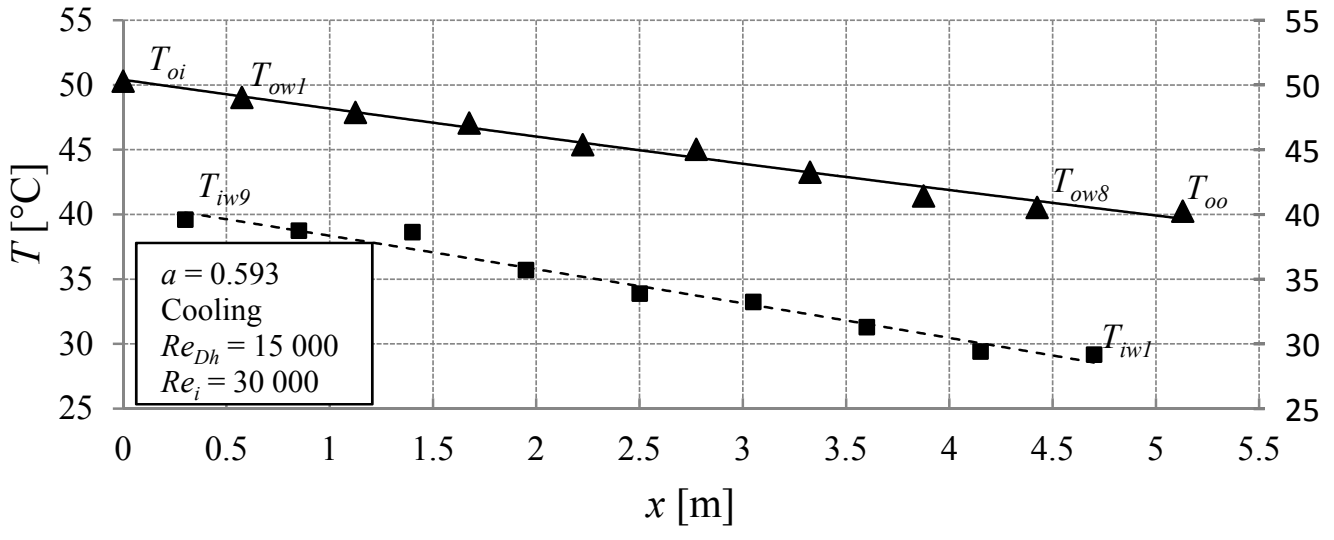

b)

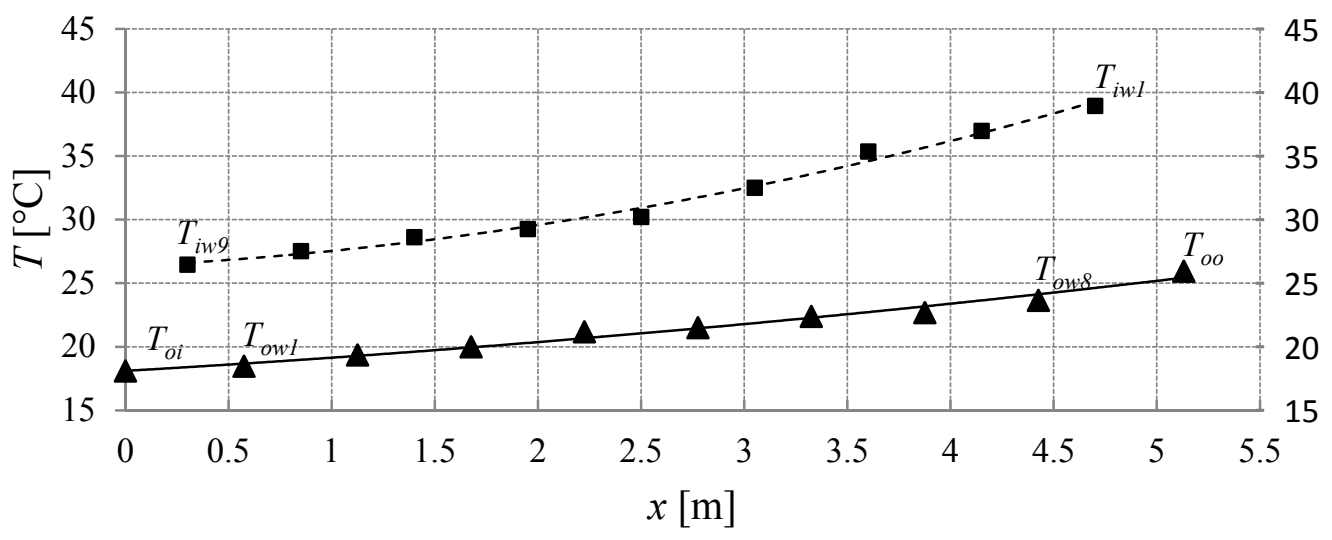

Figure 10: Inner- and outer-wall temperature profiles for a) a cooled annulus and b) a heated annulus. 


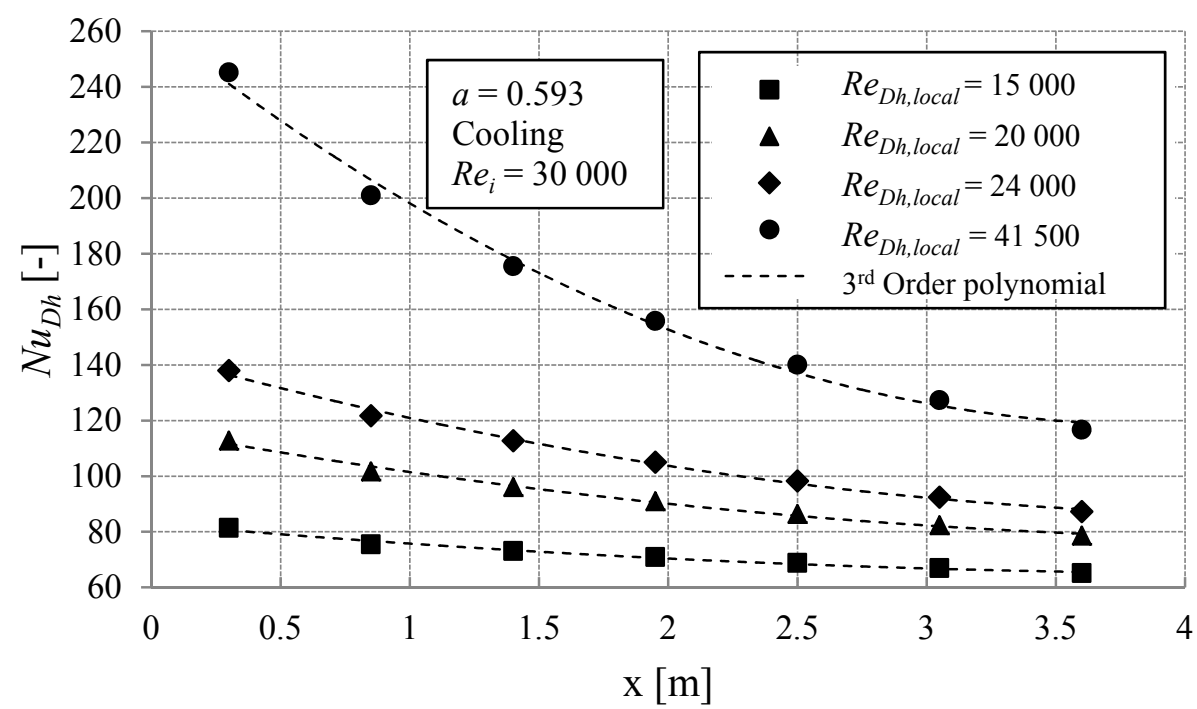

Figure 11: Nusselt numbers for various local Reynolds numbers for a cooled annulus. 


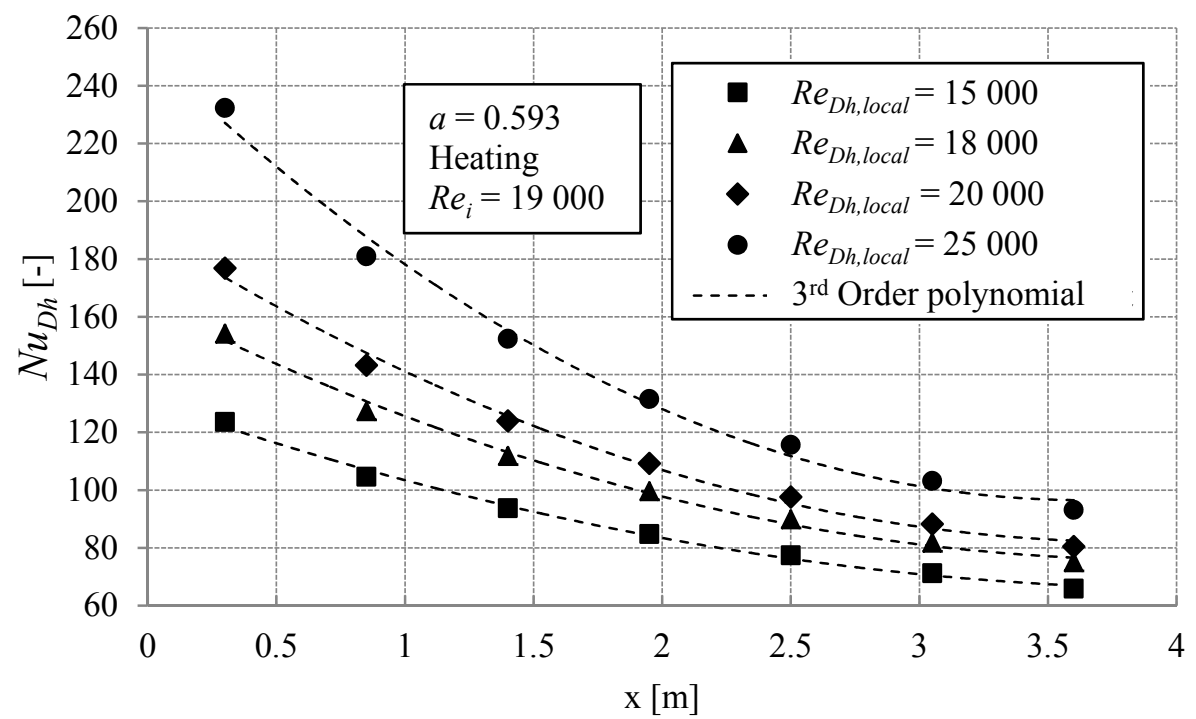

Figure 12: Nusselt numbers for various local Reynolds numbers for a heated annulus. 


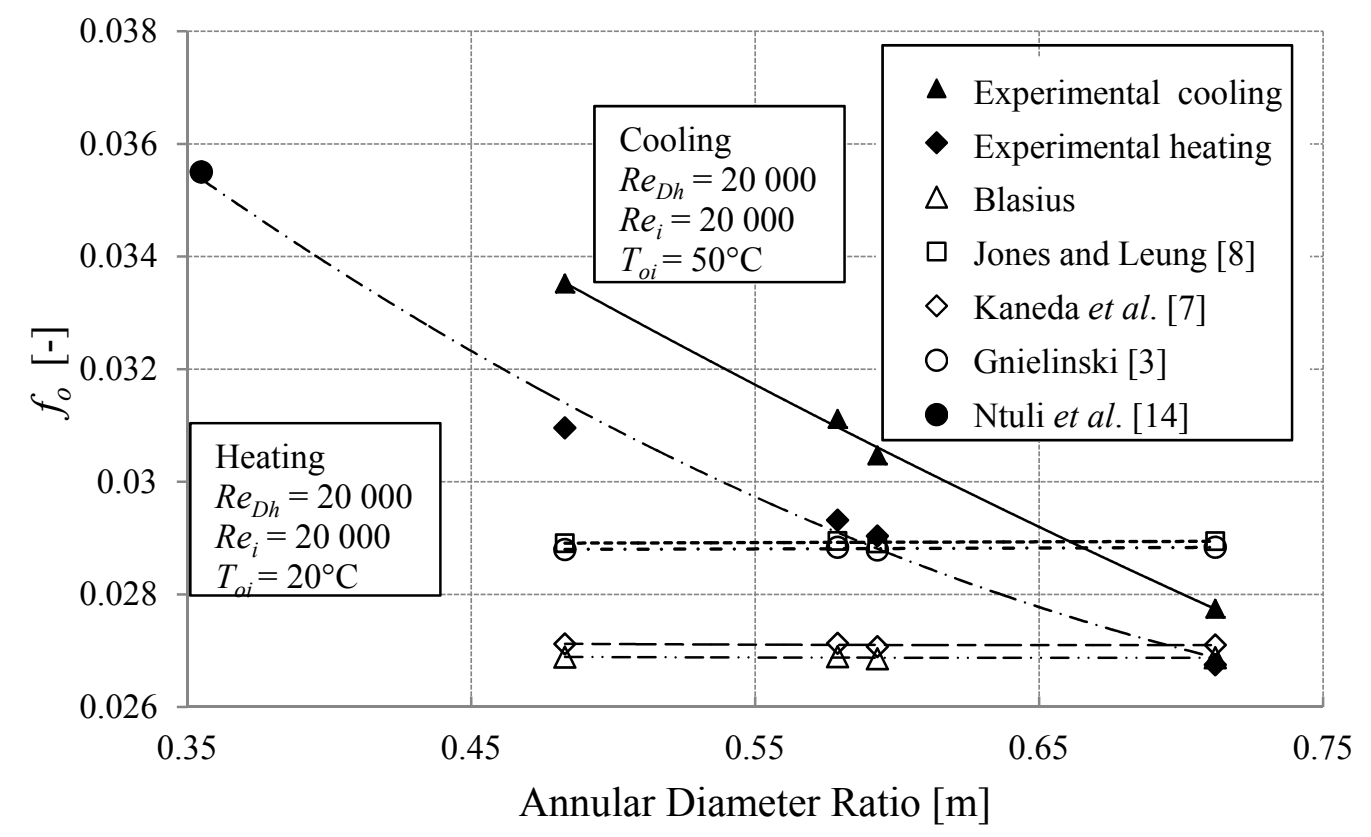

Figure 13: Friction factors for a heated and a cooled annulus. 


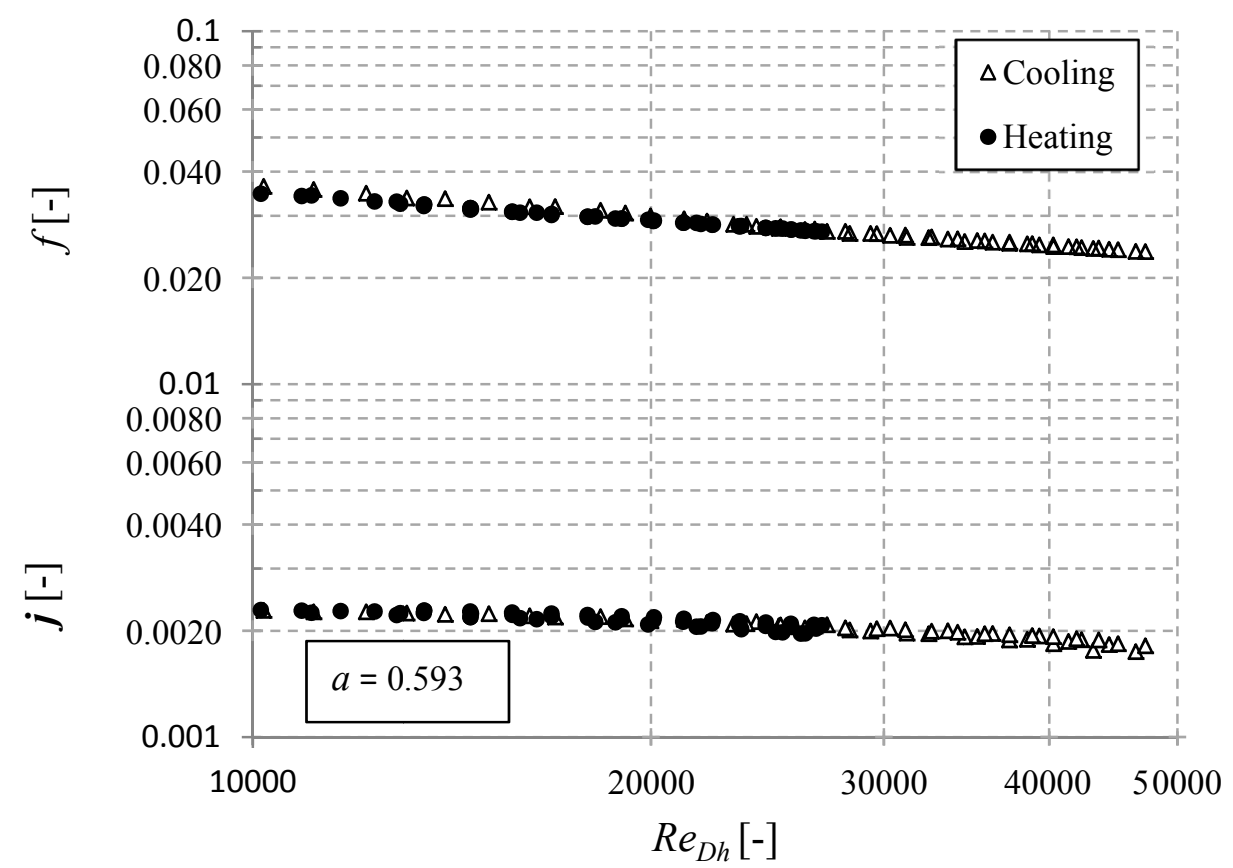

Figure 14: Colburn $\boldsymbol{j}$-factors for a heated and a cooled annulus. 


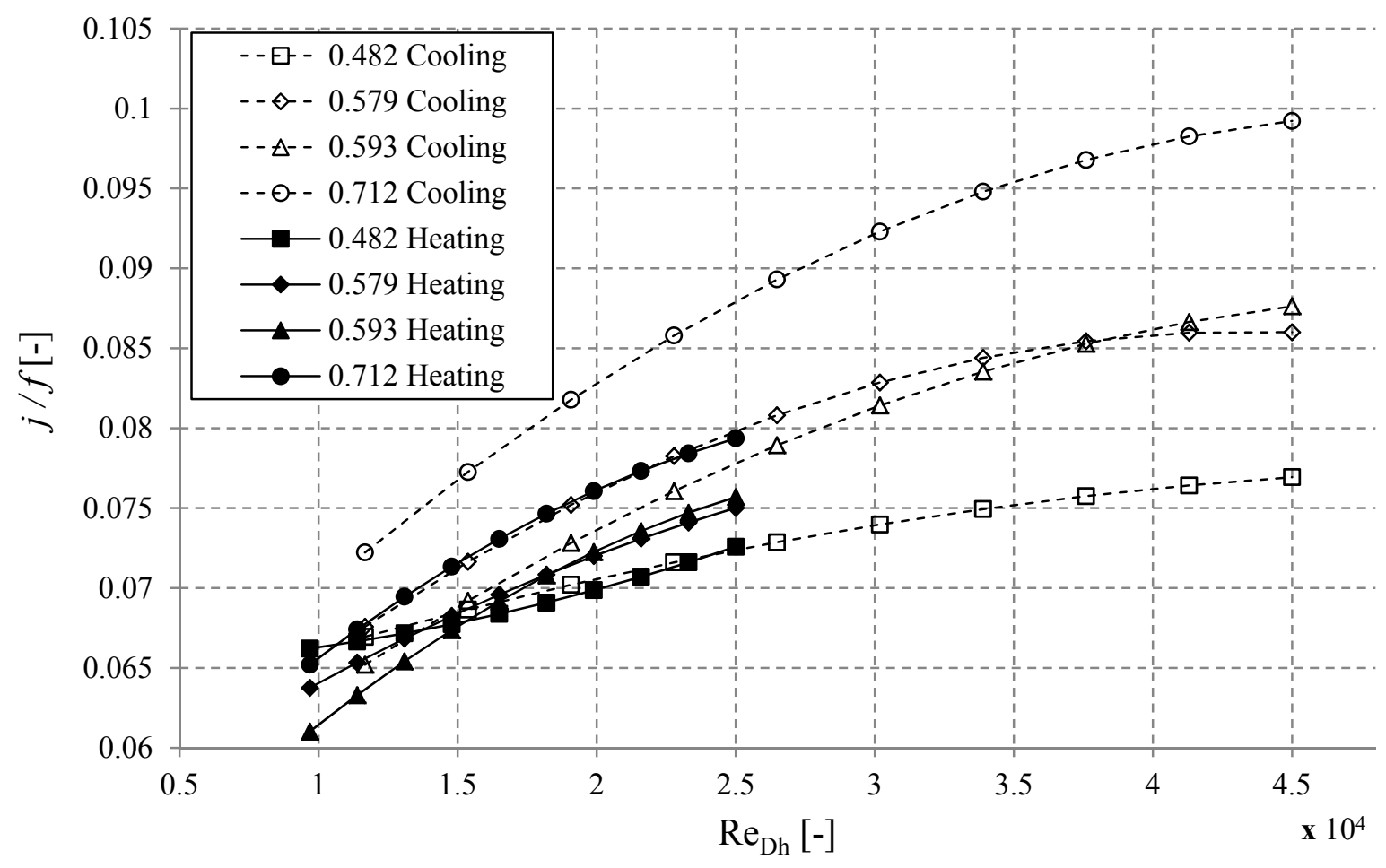

Figure 15: Ratio of Colburn $\boldsymbol{j}$-factor to experimental friction factor. 


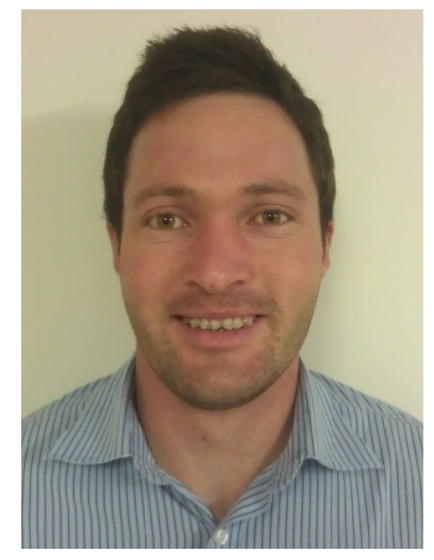

Warren van Zyl obtained his B.Eng in 2008and honours degree in 2010 in Mechanical and Aeronautical Engineering at the University of Pretoria, South Africa. He is currently busy with his master's degree in Mechanical and Aeronautical Engineering.

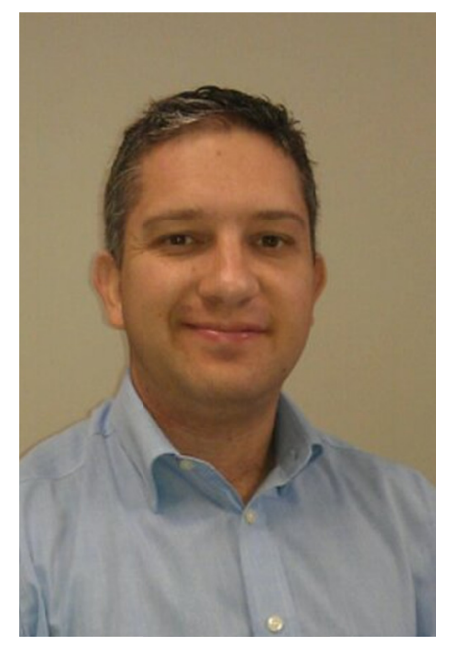

JacoDirker is asenior lecturer in the Department of Mechanical and Aeronautical Engineering at the University of Pretoria, South Africa.He obtained his $\mathrm{PhD}$ in Mechanical Engineering from the Rand Afrikaans University in Johannesburg, South Africa. His research interests include convective heat transfer in macro- and microchannels, and thermal system optimization.

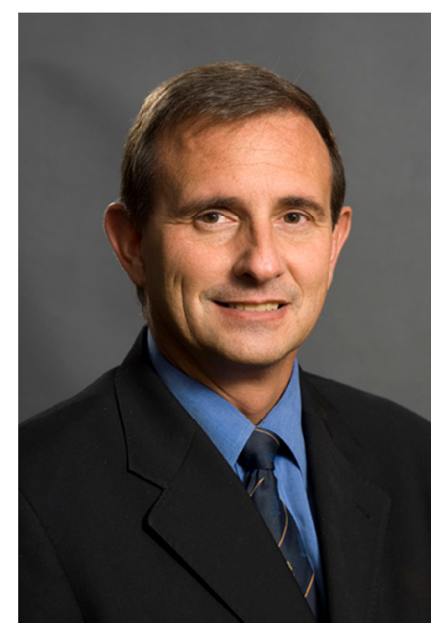

Josua Meyer is a professor and Chair of the School of Engineering and also Head of the Department of Mechanical and Aeronautical Engineering at the University of Pretoria, South Africa. He specializes in heat transfer, fluid mechanics and thermodynamic aspects of heating, ventilation and airconditioning. $\mathrm{He}$ is the author and coauthor of more than 400 articles, conference papers and patents, and has received various prestigious awards for his research. He is also a fellow or member of various professional institutes and societies and is regularly invited as a keynote speaker at local and international conferences. He has received various teaching awards as Lecturer of the Year and he has received three awards from the University of Pretoria as an exceptional achiever. In 2011, he was evaluated by the National Research Foundation (NRF) as an established researcher who enjoys considerable international recognition for the high quality and impact of his recent research outputs. He is an associate editor of Heat Transfer Engineering. 